\title{
ANÁLISE COLORIMETRICA DE AÇÚCAR MASCAVO E SUA ACEITAÇÃO NO MERCADO DE VIÇOSA-MG, BRASIL
}

\section{COLORIMETRIC ANALYSIS AND SENSORY ACCEPTANCE OF RAW SUGAR IN THE MARKET OF VIÇOSA-MG, BRAZIL}

\author{
Elvira Durán ${ }^{*}$, Ronaldo Pérez², Wilton Cardoso 3 , Omar A. Pérez ${ }^{4}$ \\ Recibido para publicación: Abril 16 de 2012 - Aceptado para publicación: Septiembre 7 de 2012
}

\begin{abstract}
RESUMO
O Brasil destaca-se pela sua produção de cana-de-açúcar. O açúcar mascavo é um nutritivo e saudável subproduto, obtido artesanalmente por agricultores familiares. Entretanto, como resultado de sua produção artesanal, o açúcar mascavo apresenta diversidade na cor. O objetivo deste estudo foi analisar a cor do açúcar mascavo e sua aceitação no mercado de Viçosa, Minas Gerais. Foram realizadas análises colorimétricas (CIELAB) e os resultados avaliados mediante análise multivariada, medidas de dissimilaridade e similaridade, e técnicas de agrupamento (programa GENES). Para a análise colorimétrica foram avaliadas duas amostras de açúcar mascavo comercializadas pela Associação Riobranquense de Produtores de Rapadura, Açúcar Mascavo, Aguardente e Melado (ARPRAM), onze obtidas de seus associados e seis amostras de marcas comerciais. Para teste de aceitação da cor pelos consumidores foram escolhidas três amostras representativas das cores: escura, semi-escura e clara. Para esta avaliação foi usada uma escala hedônica de nove pontos. Das 19 amostras analisadas, 13 apresentaram diferenças de cor visível. As amostras com maior dissimilaridade foram as de um produtor e da ARPRAM, apresentando distância euclidiana média de 16,47. As amostras com maior similaridade foram obtidas de um associado da ARPRAM e de uma marca comercial com distância de 0,44. Não houve diferença significativa no teste de aceitação de cor das amostras de açúcar mascavo. Com a análise colorimétrica foi comprovado que não há uniformidade da cor entre as amostras produzidas e comercializadas pela ARPRAM, bem como as obtidas comercialmente. Entretanto, para o consumidor as diferenças na cor não influenciam na aceitação do açúcar mascavo.
\end{abstract}

Palavras chave: açúcar mascavo, análise colorimétrica, aceitação sensorial.

\footnotetext{
'Magíster em Ciência y Tecnologia de Alimentos, docente, Universidad de Córdoba. Berástegui, Córdoba. Facultad de Medicina Veterinaria y Zootecnia, Universidad de Córdoba, Sede Berástegui Km. 5 Vía Cereté - Ciénaga de Oro - Córdoba, Colombia Telefax: (4) 7560209 - (4) 8940507.edrojas@correo.unicordoba.edu.co

${ }^{2}$ Doutor em Engenharia de Alimentos, docente Universidade Federal de Viçosa. Viçosa, MG, Brasil.

${ }^{3}$ Doutor em Bioquímica Agrícola, docente Instituto Federal de Educação, Ciência e Tecnologia do Espírito Santo, IFES, Brasil.

${ }^{4}$ Doutor em Ciência y Tecnologia de Alimentos, docente Universidad de Córdoba, Montería, Colombia.
} 


\title{
RESUMEN
}

Brasil es destacado por su producción en caña de azúcar. El azúcar mascavo es un nutritivo y saludable subproducto obtenido artesanalmente por agricultores familiares, lo que hace que presente variedad en su color. El objetivo del presente estudio fue analizar el color del azúcar mascavo y su aceptación en el mercado de Viçosa, Minas Gerais. Se realizó análisis colorimétrico (CIELAB) y los resultados fueron evaluados mediante análisis multivariada, medidas de disimilaridad y similaridad, y técnicas de agrupamiento (programa GENES). Para el análisis colorimétrico se evaluaron dos muestras de azúcar mascavo comercializadas por la Asociación Riobranquense de Productores de Panela, Azúcar Mascavo, Aguardiente y Melado (ARPRAM), once obtenidas de sus asociados y seis muestras de marcas comerciales. Para la prueba de aceptación del color por parte de los consumidores se seleccionaron tres muestras representativas de los colores: oscura, semi-oscura y clara, evaluadas mediante escala hedónica de nueve puntos. De las 19 muestras analizadas, 13 presentaron diferencias de color visible. Las muestras con mayor disimilaridad fueron las de un productor y una de las comercializadas por ARPRAM, presentando distancia euclidiana media de 16,47. Las muestras con mayor similaridad fueron las de un productor y la de una marca comercial con distancia de 0,44 . No hubo diferencia significativa en la prueba de aceptación del color de las muestras de azúcar mascavo. Con el análisis colorimétrico se comprobó que no hay uniformidad en el color entre las muestras producidas y comercializadas por la ARPRAM y las de marcas comerciales. Por otra parte, para el consumidor las diferencias en el color no influyen en la aceptación del azúcar mascavo.

Palabras clave: azúcar mascavo, análisis colorimétrico, aceptación sensorial.

\begin{abstract}
Brazil is known for its sugar cane production. Raw sugar is produced by artisanal farmers. As a result of artisanal production, raw sugar is diverse in color. The aim of this study was to analyze raw sugar color and its sensory acceptance in the market of Viçosa, Minas Gerais, Brazil. Colorimetric tests (CIELAB) were done. The results were analyzed by multivariate analysis, similarity and dissimilarity measurements and clustering techniques (GENES software). Two samples of raw sugar commercialized by Associação Riobranquense de Produtores de Rapadura, Áçucar Mascavo, Aguardente e Melado (ARPRAM), eleven samples produced of his associates and six samples from commercial brands were colorimetrically analyzed. Three representative samples of dark, semi-dark and light color were chosen to test color sensory acceptance. This assessment used a nine point hedonic scale. Of the 19 samples analyzed, 13 had visible color differences. Samples with the highest dissimilarity were from a producer and from ARPRAM, with 16.47 Euclidean distance. Samples with greatest similarity were from ARPRAM and from a commercial brand with 0.44 Euclidean distance. There was no significant difference in color sensory acceptance among the tested raw sugar samples. Colorimetric analysis confirmed a lack of color uniformity among the samples produced and marketed by ARPRAM and from the commercial brand. However, differences in color did not influence the sensory acceptance of raw sugar among consumers.
\end{abstract}

Key words: raw sugar, colorimetric analysis, sensory acceptance.

\section{INTRODUÇÃO}

O comportamento do consumo de alimentos vem apresentando mudanças significativas nos últimos anos, motivadas pelo maior nível de consciência dos consumidores para saúde, viam maior escolarização e maior acesso às informações (Gehlhar y Regmi 2005).

De acordo com a Comissão Nacional de Normas e Padrões de Alimentos (CNNPA 1978), o açúcar é a sacarose obtida por meio de cana 
ou beterraba, mediante processos industriais adequados. O produto é denominado açúcar, seguido da qualificação que corresponde ao tipo: "açúcar demerara", "açúcar cristal", "açúcar refinado", "açúcar mascavo", entre outros. O teor de sacarose diferencia um açúcar do outro, e o açúcar mascavo deve conter no mínimo 90\% de sacarose.

O açúcar mascavo é facilmente reconhecido pela sua cor (marrom acentuado) e pelo seu sabor, muito próximo ao da rapadura ou do caldo de cana. Caracteriza-se ainda por ser um açúcar no qual não ocorre o processo de clarificação do caldo e por ser ausente de adição de qualquer tipo de agente químico. Geralmente é produzido em pequenas propriedades rurais e de maneira artesanal, sendo seco ao sol ou no chão e embalado manualmente (Silva y Parazzi 2003).

Segundo o DESER (2005), o açúcar mascavo era até o século XIX o principal derivado da cana-de-açúcar; durante o século $X X$ a produção desse tipo de açúcar declinou, sendo substituída lentamente pelo açúcar branco, cristal ou refinado. Na década de 1950 a produção de açúcar mascavo se tornou insignificante, sendo produzido artesanalmente somente para consumo doméstico do próprio produtor. Entretanto, a partir da década de 1990 a demanda por açúcar mascavo ressurgiu e sua produção voltou a crescer.

O açúcar mascavo é composto de sacarose, frutose, glicose, potássio, cálcio, magnésio, fósforo, sódio, ferro, manganês, zinco, vitaminas A, B1, B12, B5, C, D2, D6 e E (Silva y Parazzi 2003).
Segundo SEBRAE (2005), os consumidores têm uma imagem positiva em relação aos produtos artesanais, apreciando seus gostos e suas práticas produtivas tradicionais; porém apontam como pontos negativos a falta de padronização e falhas no quanto à higiene.

Uma das qualidades mais importantes dos alimentos é a cor. Para a maioria dos consumidores a cor é fator significativo, determinante da aceitação dos mesmos. Na indústria alimentícia utiliza-se para verificação da cor a colorimetria e as determinações são comumente feitas com instrumentos simples, chamados colorímetros, que realizam medidas de cor a partir de valores triestímulos; os quais precisam de uma fonte luminosa (luz branca), três filtros que duplicam a resposta do olho humano e um sistema detector. Os filtros correspondem às três cores primárias (vermelho, verde e azul), e os componentes da luz branca podem ser combinados para equiparar qualquer cor (Francis 1983; Méndelez-Martínez et al. 2007).

Nos alimentos, a medida da cor pode ser representada por meio das normas internacionais, desde a reunião da Commission Internationale d'Eclairage (CIE), realizada em Paris no ano de 1931, na qual se estabeleceu uma nomenclatura conhecida como o sistema CIE. Entre as modificações desse sistema, uma das mais conhecidas e usadas é o sistema Hunter ( $L, a, b)$ e CIELAB $\left(L^{*}, a^{*}, b^{*}\right)$ (Calvo 1989; Papadakis et al. 2000).

O método proposto pela $\mathrm{CIE}$, definido em 1976, baseia-se num espaço tridimensional, de modo que cada cor é representada por um único ponto nesse espaço e é definido pelas 
coordenadas L* a* b* (Billmeyer e Saltzmann 1981; Yam e Papadakis 2004). A partir desta coordenadas, foram calculadas as coordenas $\mathrm{H}^{\circ}$ e $\mathrm{C}^{*}$, onde $\mathrm{H}^{\circ}$ representa o ângulo de tonalidade e o chroma $C^{*}$ indica a saturação ou a intensidade da cor (Gil-Muñoz et al. 1997; KONICA MINOLTA 2003).

O aumento do interesse por produtos naturais a partir da década de 1980 pelos consumidores fez com que a demanda pelo açúcar mascavo fosse evoluindo, apesar de sua cor, comparada a de outros açúcares, torná-lo menos atraente ou consumidor devido ao fato de ser um produto de elaboração artesanal e não ter uma padronização.

Porem, Cuña (2005) desenvolveu nova tecnologia destinada a conseguir diferenciação deste produto, para isso pesquisou a clarificação do caldo de cana para a fabricação de açúcar mascavo utilizando quitosana, fazendo o produto mais atraente ao consumidor, por seu aspecto sensorial.

Mesmo assim, o grau de aceitabilidade de um alimento por parte dos consumidores é afetado por fatores inerentes ao próprio indivíduo e ao meio ambiente que o circunda. A preferência por um produto está ligada aos hábitos e padrões culturais, além da sensibilidade individual, idade, fidelidade a determinadas marcas, higiene e local de consumo, tipo e número de acompanhantes, entre outros aspectos (Dasso 1999; Kotler y Keller 2006).

A análise sensorial apresenta, atualmente, técnicas bastante desenvolvidas, que encontram aplicações em várias etapas da elaboração de produtos de consumo. Os testes sensoriais podem ser classificados em quatro tipos básicos: afetivos, discriminatórios, descritivos e de qualidade (Chaves 1993; Drake 2007).

Os testes afetivos são uma importante ferramenta, pois acessam diretamente a opinião (preferência e/ou aceitabilidade) do consumidor já estabelecido ou potencial de um produto sobre características específicas desse produto ou idéias sobre ele. Por isso, são também chamados de testes de consumidor. Os testes afetivos são muito usados por produtores de bens de consumo e também por prestadores de serviços, como bancos, hospitais e mesmo pelas forças armadas em alguns países (Espinosa 2007; Ferreira et al. 2000). A utilização da escala hedônica ou da escala de atitude (FACT) é um exemplo desse tipo de teste.

A análise descritiva consiste na técnica sensorial, em que os atributos de um produto são identificados e quantificados por julgadores treinados especificamente para este propósito. A análise pode incluir todos os atributos do produto ou pode ser limitado a certos aspectos, como aroma, sabor, textura ou sabor residual (Faria y Yotsuyanagi 2002).

Neste sentido, diante do interesse e disposição de um grupo de pequenos produtores rurais da ARPRAM do município de Visconde do Rio Branco-MG, associados para melhoria da qualidade de seus produtos, dentre eles o açúcar mascavo, podendo assim competir mais fortemente no mercado, o objetivo da presente pesquisa foi analisar o padrão de cor de açúcar mascavo e sua aceitação pelos consumidores em Viçosa-MG. 


\section{MATERIAIS E MÉTODOS}

A pesquisa se caracteriza como exploratória e descritiva. A técnica adotada foi o estudo de caso, cujo alvo foi a ARPRAM situada na mesorregião da Zona da Mata de Minas Gerais. Foram avaliadas amostras de açúcar mascavo provenientes de 11 produtores associados à ARPRAM, dois tipos do açúcar comercializado pela ARPRAM e seis marcas comerciais dos concorrentes, totalizando 19 amostras. As marcas de açúcar mascavo utilizadas neste trabalho foram encontradas principalmente nas cidades de Viçosa e Belo Horizonte, em supermercados de pequeno porte e lojas de produtos naturais.

A análise colorimétrica das 19 amostras foi realizada utilizando-se um colorímetro portátil da marca MINOLTA modelo CR10, escala CIELAB, o qual mede as coordenadas: $L^{*}$, que representa a luminosidade numa escala de 0 (preto) a 100 (branco); a*, que representa uma escala de tonalidades de vermelho $(0+a)$ a verde $(0-a)$; e $b^{*}$, que representa uma escala de tonalidades de amarelo (0+b) a azul (0-b) (Billmeyer e Saltzmann 1981; Yam e Papadakis 2004).

$\mathrm{Na}$ realização das análises colorimétricas das 19 amostras utilizou-se uma placa de Petri previamente limpa e seca, sob fundo branco, onde foi colocada uma porção de 20 g de açúcar mascavo de cada amostra. A amostra foi compactada na placa de Petri. A determinação das coordenadas $L^{*}, a^{*}$ e $b^{*}$ de todas as amostras foi realizada em duplicata.

Testou-se o calorímetro portátil CR10, para certificação de que estava devidamente calibrado, medindo-se as variáveis do amido
(100 g em uma placa de Petri), utilizando-Ihe em forma perpendicular $\left(90^{\circ}\right)$ na amostra de amido para fazer a leitura. As mensurações foram divididas em duas fases: primeiramente foram avaliadas as amostras adquiridas no início do ano (mês de janeiro a março) e, na segunda fase, as amostras adquiridas no mês de outubro, para verificação exposição da situação atual da produção em relação à cor.

Os resultados obtidos dos parâmetros de cor foram analisados estatisticamente pelo programa GENES (Cruz 2004). Para avaliar se havia divergência ou não, em relação à cor, entre os açúcares mascavos provenientes dos produtores, da ARPRAM e concorrentes foram utilizados métodos de agrupamento, mediante análises multivariadas. Os métodos de agrupamento utilizam-se das medidas de similaridade (ou dissimilaridade) entre os objetos, segundo suas características (variáveis), relacionando os indivíduos ou itens em grupos, a partir de determinada técnica de agrupamento.

De acordo com os dados obtidos das leituras realizadas sobre os açúcares mascavos dos produtores associados, da ARPRAM e dos concorrentes, L*, $\mathrm{H}^{\circ}$ (ângulo Hue) e $\mathrm{C}^{*}$ (Chroma) foram utilizados para realização da análise multivariada. Os parâmetros a* e b* foram transformados nos índices ângulos Hue e Chroma, quesignificamtonalidadeeintensidade de cor, respectivamente. Seguidamente, para quantificar a dissimilaridade existente entre os 19 açúcares mascavos, em relação às três características avaliadas $\left(\mathrm{L}^{*}, \mathrm{H}^{\circ}\right.$ e $\left.\mathrm{C}^{*}\right)$, utilizou-se como medida de dissimilaridade a distância euclidiana média; para delimitação dos grupos, utilizaram-se a dispersão gráfica, 
empregando as variáveis de maior importância para as divergências assinaladas por Singh (1981), métodos de otimização de Tocher e o hierárquico, de Ward.

Para determinar a aceitação da cor do açúcar mascavo, escolheu-se aleatoriamente do total das amostras três as quais foram codificadas com números de três dígitos e embaladas em sacos transparentes de $250 \mathrm{~g}$, com base nas cores escura, correspondente ao concorrente C18 com o código 720, semi-escura comercializada pela ARPRAM, Ae12 com o código 232, e clara, do concorrente C16 com o código 525.

O teste de aceitação foi realizado em dois estabelecimentos de médio porte (supermercados Amantino e Bahamas) na cidade de Viçosa-MG, em dois dias de semana. Esses supermercados foram frequentados por consumidores de todas as classes sociais, e as amostras, avaliadas por 100 consumidores. As pessoas que faziam compras no local foram abordadas e perguntadas a respeito do interesse em participar voluntariamente do teste de aceitação.

As três amostras foram servidas de forma simultânea ao consumidor em uma bandeja de plástico branca, para avaliação da cor. Os testes foram conduzidos individualmente no supermercado, sob lâmpadas quase semelhantes à iluminação natural. O consumidor recebeu uma ficha-resposta para que avaliasse o atributo sensorial de cor do produto embalado, utilizando uma escala hedônica de nove pontos para descrever o quanto gostou ou desgostou do produto em relação à cor.
Os dados primários para obter o perfil do consumidor foram avaliados pelo programa SPSS (Statistical Package for the Social Sciences) for Windows, versão 13.0. Os resultados foram reunidos em tabelas de freqüências absolutas e relativas, e também em tabelas com cruzamentos, para os resultados mais relevantes, a fim de estudar as características levantadas, como gênero, procedência, idade, instrução, profissão, freqüência de consumo e a forma em que é consumido o açúcar mascavo, além da nota dada pelos consumidores. Os resultados foram interpretados conforme as diferenças encontradas em nível de tabelas de freqüências relativas e plotados no programa EXCEL, para fazer as respectivas figuras.

Foi realizada a Análise de Variância Univariada (ANOVA) para os dados obtidos das notas, em relação à aceitação da cor, da escala hedônica dos consumidores entrevistados nas três amostras supracitadas. Para comparação entre as amostras foi utilizado o teste de médias (Duncan). As análises estatísticas foram feitas utilizando-se o programa estatístico SAS (Statistical Analysis System-SAS Institute Inc. North Carolina, USA), versão 8.0, licenciado para a Universidade Federal de Viçosa.

\section{RESULTADOS E DISCUSÃO}

Análises colorimétricas do açúcar mascavo Na Tabela 1 são apresentados os resultados das análises de cor, nos parâmetros L*, a* e b* . Essas análises foram realizadas para medir o grau de padronização do açúcar mascavo em relação à cor durante o ano, por isso elas foram feitas em dois períodos do ano. O parâmetro E indica a visibilidade, ou seja, a percepção baseada em $L^{*}, a^{*}$ e $b^{*} . \Delta E$ representa $o$ 
Tabela 1. Resultados das análises de cor realizadas em açúcar mascavo dos produtores da ARPRAM, da ARPRAM e de concorrentes.

\begin{tabular}{|c|c|c|c|c|c|c|c|c|c|c|c|}
\hline & \multirow[b]{2}{*}{ Açúcares } & \multicolumn{3}{|c|}{$\begin{array}{c}\text { Médias da } 1^{\text {a }} \\
\text { medição (Janeiro) }\end{array}$} & \multicolumn{3}{|c|}{$\begin{array}{c}\text { Médias da } 2^{\mathrm{a}} \\
\text { medição (Outubro) }\end{array}$} & \multicolumn{4}{|c|}{$\begin{array}{l}\text { Variação ocorrida nas } \\
\text { duas medições }\end{array}$} \\
\hline & & $\mathbf{L}^{*}$ & $\mathrm{a}^{*}$ & $\mathbf{b}^{*}$ & $\mathbf{L}^{*}$ & $\mathbf{a}^{*}$ & $\mathbf{b}^{*}$ & $\Delta \mathbf{L}^{*}$ & $\Delta \mathbf{a}^{*}$ & $\Delta \mathbf{b}^{*}$ & $\Delta \mathbf{E}$ \\
\hline \multirow{11}{*}{ 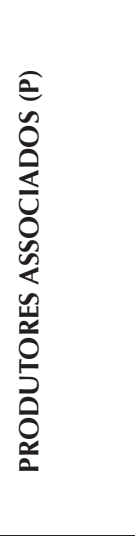 } & 1 & 52,65 & 9,05 & 28,70 & 47,55 & 9,00 & 26,10 & 5,10 & 0,05 & 2,60 & 5,72 \\
\hline & 2 & 49,55 & 10,45 & 27,35 & 49,45 & 11,15 & 29,60 & 0,10 & $-0,70$ & $-2,25$ & 2,36 \\
\hline & 3 & 56,50 & 7,20 & 27,00 & 51,85 & 9,25 & 27,40 & 4,65 & $-2,05$ & $-0,40$ & 5,10 \\
\hline & 4 & 46,40 & 13,00 & 29,30 & 45,00 & 13,75 & 29,25 & 1,40 & $-0,75$ & 0,05 & 1,59 \\
\hline & 5 & 54,35 & 7,40 & 27,00 & 54,70 & 8,45 & 28,90 & $-0,35$ & $-1,05$ & $-1,90$ & 2,20 \\
\hline & 6 & 48,75 & 14,40 & 32,80 & 48,35 & 13,30 & 31,60 & 0,40 & 1,10 & 1,20 & 1,68 \\
\hline & 7 & 41,60 & 12,10 & 25,70 & 41,20 & 12,10 & 25,85 & 0,40 & 0,00 & $-0,15$ & 0,43 \\
\hline & 8 & 47,45 & 12,80 & 30,05 & 49,25 & 11,95 & 30,00 & $-1,80$ & 0,85 & 0,05 & 1,99 \\
\hline & 9 & 54,30 & 10,85 & 27,75 & 52,25 & 11,50 & 28,05 & 2,05 & $-0,65$ & $-0,30$ & 2,17 \\
\hline & 10 & 45,45 & 9,85 & 25,55 & 41,85 & 9,65 & 22,90 & 3,60 & 0,20 & 2,65 & 4,47 \\
\hline & 11 & 44,40 & 7,60 & 22,00 & 45,50 & 8,85 & 23,35 & $-1,10$ & $-1,25$ & $-1,35$ & 2,14 \\
\hline (Ae) & 12 & 47,60 & 10,55 & 27,45 & 50,50 & 10,05 & 26,85 & $-2,90$ & 0,50 & 0,60 & 3,00 \\
\hline ARPRAM & 13 & 64,25 & 7,40 & 26,25 & 64,40 & 7,50 & 26,35 & $-0,15$ & $-0,10$ & $-0,10$ & 0,21 \\
\hline \multirow{6}{*}{ 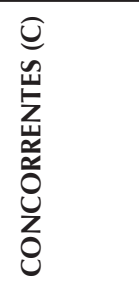 } & 14 & 51,55 & 8,00 & 24,10 & 52,40 & 8,10 & 23,95 & $-0,85$ & $-0,10$ & 0,15 & 0,87 \\
\hline & 15 & 49,35 & 10,50 & 25,90 & 51,60 & 10,25 & 26,80 & $-2,25$ & 0,25 & $-0,90$ & 2,44 \\
\hline & 16 & 59,45 & 8,25 & 22,70 & 54,70 & 6,60 & 21,15 & 4,75 & 1,65 & 1,55 & 5,26 \\
\hline & 17 & 49,90 & 10,35 & 29,00 & 52,75 & 8,35 & 25,80 & $-2,85$ & 2,00 & 3,20 & 4,73 \\
\hline & 18 & 44,75 & 13,00 & 26,80 & 45,40 & 13,90 & 28,85 & $-0,65$ & $-0,90$ & $-2,05$ & 2,33 \\
\hline & 19 & 44,30 & 11,40 & 24,70 & 51,95 & 8,80 & 23,95 & $-7,65$ & 2,60 & 0,75 & 8,11 \\
\hline
\end{tabular}

Resultados medidos em dois períodos, janeiro e setembro do açúcar de lotes e data de fabricação diferente, são expressos pela variação das variáveis $L^{*}, a^{*}$ e $b^{*}$, onde:

Eixo L* representa a luminosidade numa escala de 0 (preto) a 100 (branco); Eixo a* representa uma escala de tonalidades de vermelho $(0+a)$ a verde $(0-a)$; Eixo b* representa uma escala de tonalidades de amarelo $(0+b)$ a azul $(0-b)$.

desvio total de cor, de duas amostras, para determinado produto ${ }^{5}$.

Dos 19 açúcares mascavos dos produtores e dos concorrentes analisadas, 13 apresentaram desvio acima de médio ( $\Delta \mathrm{E}$ acima de 2 ), ou seja, quase $70 \%$ destes tiveram mudança de cor visível. Entre os produtores associados da ARPRAM, sete apresentaram o desvio de cor acima de médio, mais de $60 \%$. Dentre os concorrentes, cinco dos seis, tiveram variação de cor perceptível. A ARPRAM também apresentou desvio para seu açúcar mascavo de cor mais escura, o que era esperado visto que seus associados apresentaram desvio, e o açúcar da ARPRAM comercializado é a mistura destes associados. Analisando os resultados pode-se considerar que não existe um padrão de cor tanto ao nível dos produtores como das entidades que comercializam o produto no mercado.

O objetivo da aplicação da análise multivariada nos dados coletados da análise colorimétrica

${ }^{5} \mathrm{Em}$ termos de $\Delta \mathrm{E}$ têm-se as seguintes interpretações:

$\Delta \mathrm{E}$ entre 0 e 1 - desvio que não é normalmente visível; $\Delta \mathrm{E}$ entre 1 e 2 - pequeno desvio, só visível para olhos treinados; $\Delta \mathrm{E}$ entre 2 e 3,5 - desvio médio, também detectável por olhos não treinados; $\Delta \mathrm{E}$ entre 3,5 e 5 - desvio obvio; $\Delta \mathrm{E}$ ácima de 5 - desvio significante. 
das amostras já referenciadas foi avaliar as características na cor de açúcar mascavo medindo a distância de dissimilaridade ou similaridade, para logo fazer as agrupações de acordo à diferença na cor avaliada, de tal forma que exista homogeneidade dentro do grupo e heterogeneidade entre grupos.

Verifica-se, na Tabela 2 que os açúcares mais dissimilares foram os de número1P (produtor) e 13 Ac (ARPRAM claro), que apresentaram o maior valor de distância euclidiana média $(16,47)$. Por sua vez, os açúcares 4P (produtor) e 18C (concorrente) foram os mais similares, apresentando a menor magnitude de distância $(0,44)$.

Quando a matriz de dissimilaridade é gerada pelo programa estatístico GENES, o programa gera automaticamente uma tabela, que quantifica a contribuição relativa dos caracteres para a divergência (ou similaridade) entre os indivíduos na análise (Singh 1981). Os objetos com menor distância entre si são mais semelhantes, sendo, portanto, agrupados em um mesmo grupo; já os mais distantes participam de grupos distintos.

A contribuição relativa dos variantes para divergência segundo Singh (1981) mediante cálculo feito com médias não padronizadas correspondeu para a variável $L^{*}$ um valor de 59,25\%, a variável Ho com $18,51 \%$ e a variável $C^{*} \operatorname{com} 22,24 \%$. O que significa que a variável $L^{*}$ (luminosidade) foi responsável por cerca de $60 \%$ das diferenças ocorridas entre os açúcares. Deve-se levar em conta que acima de $70 \%$ de contribuição relativa das variáveis para diferença entre as amostras é o ideal

Tabela 2. Medidas de dissimilaridade entre os 19 açúcares mascavos, em relação aos parâmetros de cor L* (Luminosidade), C* (Chroma) e Hº (ângulo Hue), com base na distância Euclidiana Média.

\begin{tabular}{|c|c|c|c|c|c|c|c|c|c|c|c|c|c|c|c|c|c|c|c|}
\hline $\begin{array}{c}\text { Açúcar } \\
*\end{array}$ & & $2 P$ & $3 P$ & $4 P$ & $5 P$ & $6 P$ & $7 P$ & $8 P$ & 9P & $10 P$ & $11 P$ & $12 \mathrm{Ae}$ & $13 \mathrm{Ac}$ & $14 \mathrm{C}$ & $15 \mathrm{C}$ & $16 \mathrm{C}$ & $17 \mathrm{C}$ & $18 \mathrm{C}$ & $19 \mathrm{C}$ \\
\hline $1 P$ & 06 & 6,784 & 4,343 & 5,379 & 8,828 & 6,967 & 2,541 & 6,540 & 5,315 & 2,948 & 4,710 & 6,809 & 14,16 & 6,559 & 6,524 & 6,324 & 9,850 & 5,510 & 10,616 \\
\hline $2 P$ & 0 & 0 & 2,776 & 4,309 & 3,717 & 1,185 & 6,597 & 1,328 & 3,032 & 9,168 & 3,335 & 4,031 & 10,447 & 5,760 & 2,936 & 8,200 & 7,610 & 3,992 & 8,149 \\
\hline $3 \mathbf{P}$ & & & 0 & 2,478 & 5,716 & 2,657 & 3,896 & 2,778 & 1,502 & 6,449 & 2,620 & 4,409 & 11,912 & 5,510 & 3,457 & 7,500 & 8,378 & 2,278 & 9,024 \\
\hline $4 \mathrm{P}$ & & & & 0 & 7,723 & 3,560 & 3,633 & 4,708 & 2,526 & 6,523 & 5,030 & 6,567 & 13,890 & 7,751 & 5,518 & 9,807 & 10,63 & 0,437 & 11,231 \\
\hline $5 \mathrm{P}$ & & & & & 0 & 4,525 & 9,430 & 3,023 & 5,647 & 11,441 & 4,236 & 3,001 & 6,880 & 4,535 & 2,955 & 7,285 & 4,592 & 7,361 & 4,968 \\
\hline $6 \mathrm{P}$ & & & & & & 0 & 6,367 & 1,922 & 2,486 & 9,066 & 3,855 & 4,521 & 10,999 & 6,304 & 3,325 & 8,984 & 8,310 & 3,198 & 8,812 \\
\hline $7 \mathrm{P}$ & & & & & & & 0 & 6,629 & 4,607 & 2,985 & 5,507 & 7,557 & 15,187 & 7,853 & 6,926 & 8,566 & 11,199 & 3,904 & 11,910 \\
\hline $8 \mathrm{P}$ & & & & & & & & 0 & 2,737 & 8,940 & 2,393 & 2,719 & 9,461 & 4,510 & 1,608 & 7,290 & 6,446 & 4,353 & 6,991 \\
\hline $9 P$ & & & & & & & & & 0 & 7,042 & 2,999 & 4,124 & 11,444 & 5,423 & 3,109 & 8,073 & 8,206 & 2,160 & 8,769 \\
\hline $10 \mathrm{P}$ & & & & & & & & & & 0 & 7,226 & 9,139 & 16,469 & 8,791 & 8,838 & 8,568 & 12,206 & 6,757 & 12,928 \\
\hline $11 \mathrm{P}$ & & & & & & & & & & & 0 & 2,254 & 9,786 & 2,989 & 1,921 & 5,231 & 5,894 & 4,782 & 6,593 \\
\hline 12Ae & & & & & & & & & & & & 0 & 7,643 & 2,011 & 1,205 & 5,578 & 4,083 & 6,224 & 4,665 \\
\hline $13 \mathrm{Ac}$ & & & & & & & & & & & & & 0 & 7,712 & 8,471 & 9,959 & 4,542 & 13,493 & 3,780 \\
\hline $14 \mathrm{C}$ & & & & & & & & & & & & & & 0 & 3,081 & 3,928 & 3,450 & 7,469 & 4,150 \\
\hline $15 \mathrm{C}$ & & & & & & & & & & & & & & & 0 & 6,377 & 5,201 & 5,157 & 5,751 \\
\hline $16 \mathrm{C}$ & & & & & & & & & & & & & & & & 0 & 5,498 & 9,665 & 6,237 \\
\hline $17 \mathrm{C}$ & & & & & & & & & & & & & & & & & 0 & 10,302 & 0,808 \\
\hline $18 \mathrm{C}$ & & & & & & & & & & & & & & & & & & 0 & 10,881 \\
\hline $19 \mathrm{C}$ & & & & & & & & & & & & & & & & & & 0 & \\
\hline
\end{tabular}


para escolher as variáveis representativas. Assumindo que as variáveis L* $(59,25 \%)$ e C* $(22,24 \%)$ juntas são responsáveis por mais de $80 \%$ das diferenças entre as amostras, pode-se gerar um gráfico de dispersão representativo em duas dimensões (2D).

Na Figura 1 apresenta-se o gráfico de dispersão com base no padrão dos pontos pode-se determinar se existe algum relacionamento entre as duas variáveis; plotando os açúcares correspondentes, permite-se ainda classificar estes em grupos, com base em similaridade ou dissimilaridade, para as duas variáveis. $\mathrm{O}$ gráfico de dispersão dos açúcares com base nos componentes de maior importância relativa foi gerado pelo programa GENES.

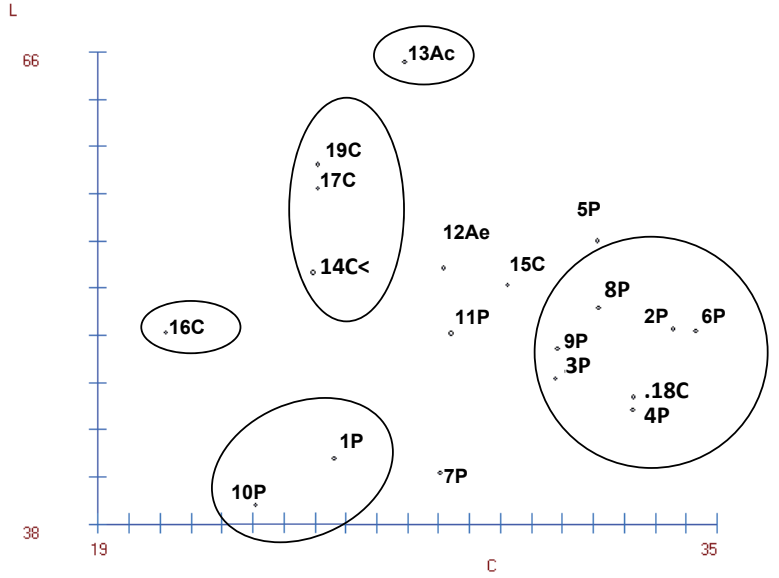

$L^{*}$ e $C^{*}$ são as variáveis representativas das diferenças entre as amostras de açúcar mascavo,onde: Eixo $L^{*}$ representa a luminosidade numa escala de preto a branco. Eixo $\mathrm{C}^{*}$ chroma representa a saturação ou intensidade, sendo Chroma $=\left(\mathrm{a}^{2}+\right.$ $\left.\mathrm{b}^{2}\right)^{1 / 2}$ onde $\mathrm{a}^{*}$ representa uma escala de tonalidades de vermelho $(0+a)$ a verde $(0-a), e$ e $*$ representa uma escala de tonalidades de amarelo $(0+b)$ a azul $(0-b)$.

Figura 1. Gráfico de dispersão 2D, relacionando as variáveis $L^{*}$ (luminosidade) e $C^{*}$ (Chroma), para a distribuição das amostras de açúcares provenientes de produtores associados (P); ARPRAM escuro (Ae); ARPRAM claro (Ac); concorrentes (C).
Verifica-se que os açúcares estão muito dispersos, podendo-se visualizar subjetivamente pelo menos cinco grupos, com base na proximidade e, ou, distância entre os açúcares plotados no gráfico. Os açúcares que se destacam são os de número 13Ac (ARPRAM/ claro) e 16C (concorrente), que estão distantes dos demais (com maior distância entre si), demonstrando claramente uma classificação deste em grupos distintos.

Para as análises de agrupamentos realizados com a utilização da matriz de distância, temse primeiramente pelo método hierárquico de Ward, representado na Figura 2 no dendrograma, tomando por base as mudanças discrepantes de níveis, ou seja, uma distância horizontal grande de um grupo para o outro a formação de dois grupos principais.

No entanto, fixo-se uma distância próxima de 20 (linha preta), o que significa considerar esta distância de dissimilaridade como a distância máxima para classificar os indivíduos (açúcares) no mesmo grupo, pode-se considerar pelo menos nove grupos diferentes. Isso é mais real, visto que a análise de dispersão anterior mostrou uma distribuição muito irregular, que não caracterizava somente dois grupos. A grande quantidade de grupos mostra que os açúcares divergem muito em relação a estas três variáveis, $\mathrm{L}^{*}, \mathrm{C}^{*} \mathrm{e} \mathrm{H}^{\text {o }}$; assim, não existe uma padronização de cor para os açúcares mascavos.

Numa análise intergrupos, o açúcar do concorrente 16C e ARPRAM claro 13Ac, sozinhos em um grupo, foram visualizados no gráfico de dispersão. Ainda, observa-se somente um grupo formado somente por concorrentes (17C e 19C). 


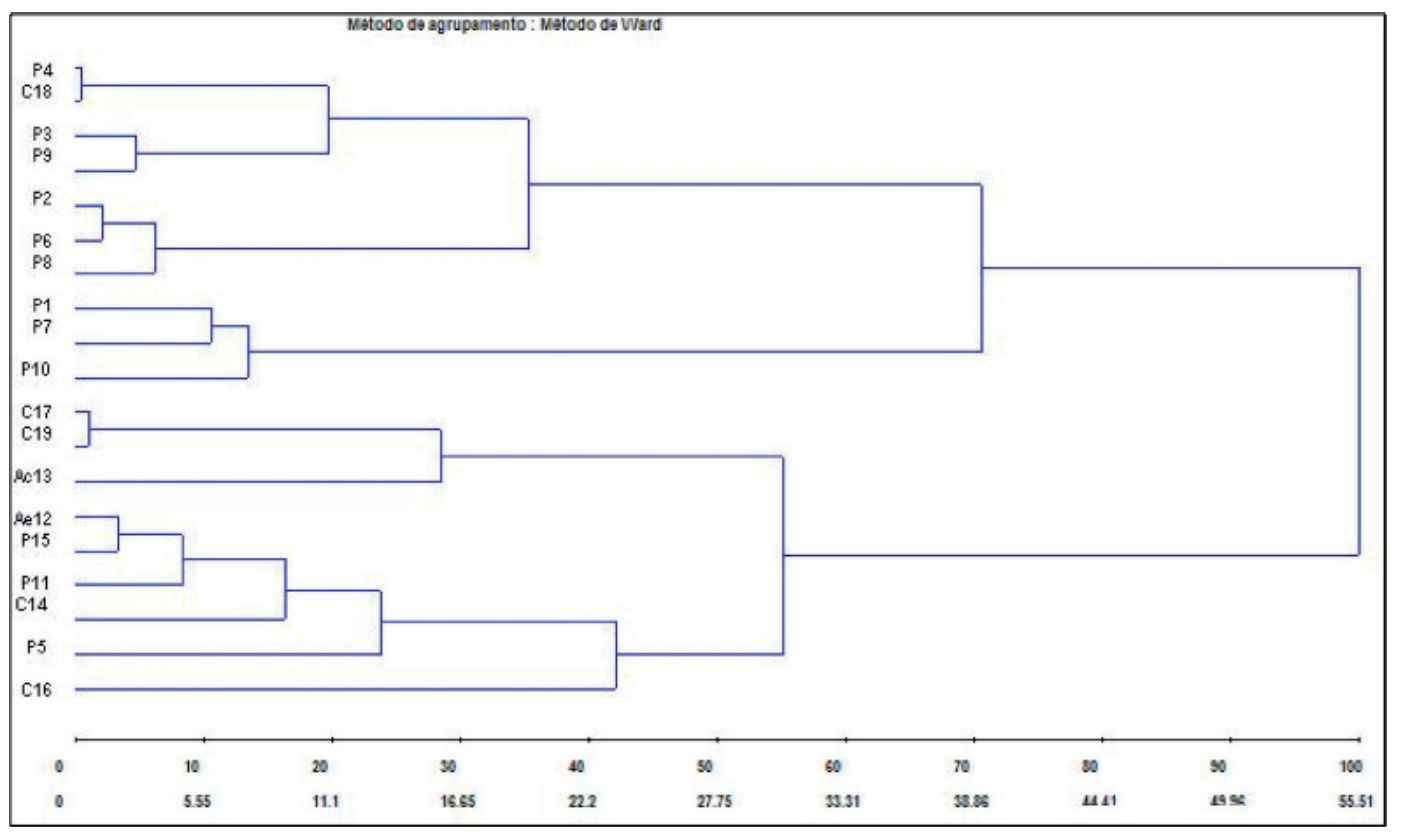

Figura 2. Dendrograma obtido do agrupamento pelo método Ward, na análise multivarida dos parâmetros de cor ( $L^{*}$ : Luminosidade, $\mathrm{H}^{\circ}$ : ângulo Hue, e $\mathrm{C}^{*}$ : Chroma ), medidos das 19 amostras do açúcar mascavo dos produtores (P); ARPRAM escuro (Ae); ARPRAM claro (Ac); e concorrentes (C).

Realizando uma análise intragrupo, com base no valor das variáveis $L^{*}, H^{\circ}$ ou $C^{*}$, percebese que os açúcares provenientes da ARPRAM e seus associados estão dispersos entre os concorrentes; era esperado que eles estivessem todos em um mesmo grupo, pois são da mesma região, e o açúcar ARPRAM é resultado da mistura destes. Deve-se ressaltar então, juntamente com os dados de $\Delta \mathrm{E}$, que não há padronização dos açúcares, na produção e nem nas misturas destes.

Pelo método de otimização de Tocher, utilizando como medida de similaridade a distância euclidiana média, há uma grande quantidade de grupos que foram selecionados por sua similaridade; assim, verifica-se novamente que os açúcares mascavos não estão padronizados em relação à cor. Apesar de um mesmo número de grupos ter sido criado no dendrograma pelo método de Ward, existe diferença nos componentes destes grupos.
Os métodos de otimização, como no caso de Tocher, diferem, basicamente, dos hierárquicos, como no caso do método de Ward, pelo fato de os grupos formados serem mutuamente exclusivos, ou seja, serem independentes, uma vez que eles não são relacionados. Por esse motivo, os métodos de otimização são mais confiáveis do que os hierárquicos, além do fato de que, nestes últimos, os grupos formados são identificados subjetivamente (Amaral e Thiébaut 1999; Cruz 2004).

\section{Teste de aceitação do açúcar mascavo}

Como objetivo de avançar na avaliação de produtos comercializados, o teste sensorial foi realizado com o intuito de verificar se a cor do açúcar mascavo influi no consumidor em sua aceitabilidade.

Identificou-se que, dos 100 consumidores respondentes, 59\% foram mulheres e 41\% homens, apresentando assim boa proporção. 
A procedência e residência dos consumidores entrevistados, a grande maioria (83\%) é natural do Estado de Minas Gerais (MG) e o restante (17\%) é de outros Estados (São Paulo, Espírito Santo, Rio de Janeiro, Bahia, Goiás, Brasília, Paraná).

No resultado da análise de variância realizada mediante o programa estatístico SAS, para as três amostras de açúcar mascavo, tendo em conta as notas dadas pelos consumidores mediante escala hedônica, não houve diferença significativa; portanto, os valores dados pelos consumidores entrevistados na cor dos três tipos de açúcar mascavo, estatisticamente, não apresenta diferença entre si. Contudo, segundo o resultado da ANOVA, para o consumidor não há diferenciação de cor entre as amostras avaliadas.

No teste de comparação de médias (Duncan) não houve diferença significativa (Tabela 3) em nível de $5 \%$ de significância entre as três amostras de açúcar mascavo $(p>0,05)$ em relação ao atributo cor, ou seja, as três amostras não diferem entre si estatisticamente. Logo, reafirma-se que para o consumidor a cor do açúcar mascavo não influi na sua escolha, apesar do afirmado por Dasso (1999) e Kotler y Keller (2006) em que a preferência de um produto

Tabela 3. Resultados das comparações das médias das três amostras de açúcar mascavo escura do concorrente C18 (código 720), semiescura da ARPRAM Ae12 (código 232), e clara do concorrente C16 (código 525).

\begin{tabular}{ccc}
\hline Amostras & Código & Média \\
\hline C16 & 525 & $6,71 \mathrm{a}$ \\
Ae12 & 232 & $6,55 \mathrm{a}$ \\
C18 & 720 & $6,24 a$ \\
\hline
\end{tabular}

*Médias seguidas de pelo menos uma mesma letra, na linha não diferem significativamente entre si pelo teste de Duncan ao nível de $5 \%$ de probabilidade $(P>0,05)$. está ligada aos hábitos e padrões culturais, e a maioria dos entrevistados foi de MG.

\section{CONCLUSÕES}

Tendo em vista os resultados das análises colorimétricas, pode-se observar que as amostras apresentaram diferentes formas de cor no açúcar mascavo, demonstrando que não há uniformidade entre os grupos analisados (produtores associados, ARPRAM, concorrentes).

O açúcar mascavo não está consolidado no mercado enquanto produto. O consumidor, de modo geral, não reconhece ou, mesmo, não conhece o "produto" açúcar mascavo. Além disso, demonstrou-se que a cor do açúcar mascavo não possui um padrão específico no mercado, o que pode dificultar a distribuição em determinados nichos de mercado, sendo notável a diferença do produto nos dois períodos de safra da cana-de-açúcar, como foi demonstrado nas amostras analisadas.

A ARPRAM deve manter um só padrão da cor de açúcar mascavo para o posicionamento do produto na mente do consumidor, além de ter o apoio promocional deste em sua divulgação e torná-lo conhecido em todas as camadas sociais; é preciso ofertá-lo em condições de qualidade e quantidade que atenda a essa demanda latente, ainda não explicitada pelo consumidor, e transformá-la em oportunidade crescente de negócio.

A falta de padronização prejudica o posicionamentonomercadoanteoconsumidor, o que algumas vezes o leva a rejeitar o produto. Para isso, é necessário trabalhar 
conjuntamente (produtor-comercializadores), de forma a definir os padrões de cor aceitos pelos consumidores de cada região.

\section{REFERÊNCIAS}

Amaral, J. e Thiébaut, J. 1999. Análise multivariada na avaliação da diversidade em recursos genéticos vegetais. Universidade Estadual do Norte Fluminense, Campos dos Goytacazes UENF, CCTA, p55.

Billmeyer, F. e Saltzmann, M. 1981. Principles of color technology. John Wiley \& Son, New York, p240.

Calvo, C. 1989. Atlas de color: fundamentos y aplicaciones. Revista de Agroquímica y Tecnología de Alimentos 29(1):15-29.

Chaves, J. 1993. Análise sensorial: histórico e desenvolvimento. Editora UFV, Viçosa, MG, p31.

\section{Comissão Nacional de Normas e Padrões para} Alimentos CNNPA. 1978. Resolução $N^{\circ}$ 12: Normas técnicas especiais do Estado de São Paulo, revistas pela CNNPA, relativas a alimentos (e bebidas), para efeito em todo território brasileiro. http:// www.anvisa.gov.br/legis/resol/12_78. pdf [22 julho 2006].

Cruz, C.D. 2004. Programa GENES: versão Windows. Aplicativo computacional em genética e estatística. Editora UFV. Universidade Federal de Viçosa. http:// www.ufv.br/dbg/genes/genes.htm html [20 agosto 2006].
Cuña, B. 2005. Utilização de Quitosana no processo de clarificação do caldo de cana para fabricação de açúcar do tipo mascavo. Dissertação de Mestrado em Ciência e Tecnologia de Alimentos. Universidade Federal de Viçosa-UFV, Viçosa, MG, Brasil.

Dasso, I. 1999. Qué ponemos en juego al degustar un alimento? La alimentación Latinoamericana 33:34-36.

Departamento de Estudos Sócio-Econômicos Rurais DESER. 2005. A Conjuntura da produção de cana-de-açúcar no Brasil e a dinâmica das exportações de açúcar no mercado mundial. Estudo Exploratório 04. Curitiba.

Drake, M. 2007. Invited review: sensory analysis of dairy foods. Journal of Dairy Science 90(12):4925-4937.

Espinosa, M. 2007. Evaluación Sensorial de los Alimentos. Ciudad de la Habana: Universidad de la Habana. Editorial Universitaria, Cuba, p129.

Faria, E. y Yotsuyanagi, K. 2002. Técnicas de análise sensorial. Laboratório de Referência em Análises Físicas, Sensoriais e Estatística-LAFISE / Instituto de Tecnologia de Alimentos-ITAL, Campinas, p116.

Ferreira, V., Almeida, T., Pettinelli, M., Silva, M., Chaves, J. e Barbosa, E. 2000. Análise Sensorial: Testes discriminativos e afetivos. (Manual: Série Qualidade), Sociedade Brasileira de Ciência e 
Tecnologia de Alimentos-SBCTA, Campinas, p127.

Francis, F. 1983. Colorimetry of foods. In Physical properties of foods. Peleg, M and Bagley, E.B., eds., AVI Publishing Company, Westport, p105-123.

Gehlhar, M. y Regmi, A. 2005. New directions in global food markets, USDA, Agriculture Information Bulletin 794. http://www.citrussa.co.za/news/ documents/New\%20Directions\%20 in\%20Global\%20Food\%20Markets.pdf [15 setembro 2006].

Gil-Muñoz, R., Gómez-Plaza, E., Martínez, A., \& López-Roca, J. M. 1997. Evolution of the CIELAB and other spectrophotometric parameters during wine fermentation. influence of some pre and postfermentative factors. Food Research International 30(9):699-705.

KONICA MINOLTA. 2003. Comunicación precisa de los colores. Konica Minolta Sensing, Inc. http://www2. konicaminolta.eu/eu/Measuring/pcc/es/ part4/04.html [15 noviembre 2011].

Kotler, P. y Keller, K. 2006. Dirección de Marketing. $12^{\mathrm{a}}$ ed. México: Pearson Education, S.A.

Méndelez-Martínez, A., Britton, G., Vicario, I. and Heredia, F. 2007. Relationship between the colour and the chemical structure of carotenoid pigments. Food Chem. 101:1145-1150.
Papadakis, S., Abdul-Malek, S., Kamdem, R. and Yam, K. 2000. A versatile anda inexpresive technique for meansuring coloro of foods. Food Technology 54(12):48-54.

\section{Serviço Brasileiro de Apoio às Micro e Pequenas} Empresas SEBRAE. 2005. O novo ciclo da cana: Estudo sobre a competitividade do sistema agroindustrial da canade-açúcar e prospecção de novos empreendimentos, Rede de Centros Internacionais de Negócios-IEL/NC, Brasília, ISBN 85-87257-18-8. http:// www.ie.ufrj.br/infosucro/biblioteca/ can_IELSebrae_NovoCiclo.pdf novembro 2006].

Silva, A. y Parazzi, C. 2003. Monitoramento microbiológico do açúcar mascavo. Resumos memórias XI Congresso de Iniciação Científica da Universidade Federal de São Carlos-UFSCar. Anais. São Carlos.

Singh, D. 1981. The relative importance of characters affecting genetic divergence. Ind. J. Genet. Plant Breed 41:237-245.

Yam, K., e Papadakis, S. 2004. A simple digital imaging method for measuring and analyzing color of food surfaces. Journal of Food Engineering 61(1):137-142. 